\title{
SISTEMA NACIONAL DE EDUCAÇÃO: DESAFIO PARA UMA EDUCAÇÃO IGUALITÁRIA E FEDERATIVA
}

\author{
Carlos Roberto Jamil Cury*
}

\begin{abstract}
RESUMO: Este artigo pretende indicar, seja do ponto de vista histórico-social, seja do ponto de vista jurídico-político, as barreiras pelas quais o Brasil jamais logrou êxito em instituir um sistema nacional de educação tal como outros países o fizeram. Do ponto de vista histórico-social, a barreira nasce da atávica desigualdade social cujo peso se fez presente na educação e, do ponto de vista jurídico-político, a forma histórica com que se revestiu nosso federalismo gerou uma interpretação de que tal sistema ofenderia a autonomia dos entes federativos estaduais e municipais. A busca por um sistema nacional de educação deve enfrentar, sobretudo, a barreira jurídico-política.

Palavras-chave: Sistema Nacional de Educação. Sistema de educação e federalismo. Sistema de educação e desigualdade Social.
\end{abstract}

\section{BRAZILIAN EDUCATION SYSTEM:}

THE CHALLENGE OF AN EGALITARIAN AND FEDERATIVE EDUCATION

ABSTRACT: This paper appoints the obstacles to build a National Education System in Brazil. From the historical and social points of view, these barriers arise from our inveterate inequality whose effects are still being felt. From the political and juridical points of view, a National Education System appears as an intrusion into federalism. Building this system requires facing these obstacles, especially the political-juridical ones.

Key words: National Education System. Education system and federalism. Education system and inequality.

Doutor em Educação e professor adjunto da Pontifícia Universidade Católica de Minas Gerais (PUC-MG).E-mail: crjcury.bh@terra.com.br 


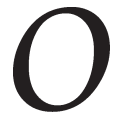

$s$ três pequenos trechos a seguir pretendem expressar aqueles que podem ser considerados os grandes desafios para a construção de um sistema nacional de educação que contenha a virtude da igualdade e a execução federativa. Afinal, tal sistema (nacional) não teve sucesso em sua inscrição legal em nosso país, ainda que muitos educadores e muitos movimentos o tivessem como meta para uma melhor qualidade da educação nacional. Tais desafios se impõem como verdadeiras barreiras.

(...) o divórcio entre as entidades que mantêm o ensino primário e profissional e as que mantêm o ensino secundário e superior vai concorrendo insensivelmente, como já observou um dos signatários deste Manifesto, "para que se estabeleçam no Brasil dois sistemas escolares paralelos, fechados em compartimentos estanques e incomunicáveis, diferentes nos seus objetivos culturais e sociais, e, por isto mesmo, instrumentos de estratificação social". (Manifesto dos Pioneiros da Educação Nova, 1932, p. 40)

O poeta municipal discute com o poeta estadual

Qual deles é capaz de bater o poeta federal

Enquanto isso o poeta federal tira ouro do nariz.

("Política literária", Carlos Drummond de Andrade)

Quero trazer-vos, com a minha presença e com a minha palavra, a afirmação de que o governo, mais do que nunca, se há de interessar pelo problema da educação nacional. Estais agora aqui congregados, sois todos profissionais e técnicos. Pois bem: estudai com dedicação; analisai com interesse todos os problemas da educação; procurai encontrar a fórmula mais feliz de colaboração do Governo Federal com o dos estados que tereis na atual administração todo o amparo ao vosso esforço. (Vargas, 1931, p. 5). (Getúlio Vargas, chefe do governo provisório, na sessão inaugural da IV Conferência Nacional de Educação, Palácio Tiradentes, 13 de dezembro de 1931)

O primeiro desafio está posto pelo caráter de nossa sociedade, evidenciado no texto do Manifesto. A expressão "estratificação social", de algum modo, está apontando para o sistema social que subjaz aos dois sistemas escolares paralelos... Com efeito, o capitalismo é uma forma histórica de organização da existência social na qual se radica um sistema de produção de tal modo que os capitalistas, proprietários dos meios de produção, mesmo competindo entre si, regulamentam a organização do trabalho. De outro lado, os trabalhadores, também concorrendo 
entre si na busca por trabalho, não possuem o direito institucional à alocação ou distribuição dos produtos da organização do trabalho (Przeworski, 1989, p. 24). Resulta daí uma desigualdade sistêmica que é congênita à sociedade capitalista ainda que dentro de um movimento contraditório.

Dessa forma, o conceito de sistema único de educação ou mesmo o de sistema unificado de educação tem como desafio maior o horizonte da igualdade, cujo motor maior não se radica na escola, mas no próprio sistema social.

A participação política, mesmo sendo uma oportunidade limitada (ainda que não fechada) de ampliação de direitos, foi e continua a ser a via institucionalizada da democracia política de defesa de interesses dos trabalhadores no sentido da redução das desigualdades.

Nesse movimento, é crucial o papel de um Estado capaz de garantir (ou não) um espaço para a defesa de direitos importantes para a participação política na vida social. E a educação, como afirma Marshall (1967), é um direito que abre o campo para se ter novos direitos.

Ora, essa desigualdade, própria da dualidade social, repercutiu e ainda repercute, a partir de nossa história nacional, na educação, mesmo que esta última, proclamada direito social, tenha sido fruto de longa conquista democrática. $\mathrm{O}$ ordenamento jurídico pode ser um bom patamar de leitura e de compreensão de como a desigualdade impactou a educação escolar.

Nossa Constituição Imperial de 1824, no capítulo das Garantias dos Direitos Civis e Políticos dos Cidadãos Brasileiros, reconhece, no artigo 179, XXXII, como direito desses cidadãos a instrução primária gratuita. Certamente é admirável esse capítulo, 35 anos após a Revolução Francesa e a proclamação dos direitos do homem e do cidadão. Contudo, essa admiração deixa de ser ingênua quando se lêem outros artigos da mesma Constituição. $\mathrm{O}$ artigo $6^{\circ}$ desta, ao destinar o para quem dessa cidadania, define como cidadãos brasileiros os que no Brasil tiverem nascido, quer sejam ingênuos ou libertos. Ora, os ingênuos são os que nasceram livres, filhos de pais livres, e naturais do país. São cidadãos ex generatione e ex jus soli. Já os libertos são aqueles alforriados que, libertando-se da escravidão, recuperaram a sua condição de homens livres. Assim, por oposição, a Constituição Imperial não reconhece os escravos como cidadãos. Desse modo, o estatuto da escravatura, tacitamente 
acolhido na Constituição, tem esse outro - por abjeto que seja - como objeto, propriedade, peça semovente e mercadoria.

Outro momento tácito de reconhecimento da escravidão está no mesmo artigo 179, XIX, que abole os açoites, a tortura, a marca de ferro quente e todas as mais penas cruéis.

Dessa concepção hierárquica, abominável, de etnias "naturalmente" destinadas ao trabalho escravo não se pode excluir também a forma de opressão que atingiu os índios. Para as elites, seu "estágio", na escala evolutiva do processo civilizatório, é o de hordas selvagens. $\mathrm{O}$ Decreto Imperial n. 1.318 de 1854, regulamentando a Lei n. 601, conhecida como Lei de Terras, compreende os índios como aptos a serem segregados em aldeamentos para efeito de civilização e de catequese, de acordo com o artigo 11 do Ato Adicional de $1834 .{ }^{1}$

À época da independência, por exclusão socioétnica, $40 \%$ dos habitantes não tinham acesso à educação como também não eram considerados cidadãos. ${ }^{2}$

Se a isso ajuntarmos as mulheres, cuja concepção organicista da época as limitava a uma cidadania passiva, então o universo dos não-cidadãos ou cidadãos imperfeitos sobe consideravelmente. À época, o direito de voto, privativo do sexo masculino, regia-se pelo voto censitário, no caso baseado nos recursos pecuniários ou territoriais do seu possuidor.

Decorrente do conjunto dessas limitaçôes, a Lei Provincial n. 1 de 2/1/1837, do Rio de Janeiro, escrevia em seu artigo 3º: "São proibidos de freqüentar as escolas públicas: $1^{\circ}$ : todas as pessoas que padecerem de moléstias contagiosas; $2^{\circ}$ : os escravos e os pretos africanos, ainda que sejam livres ou libertos (...). ${ }^{3}$

Não é de se admirar, então, que a Revolução de 1930 haja trazido esperanças para o futuro do país. O Manifesto dos Pioneiros da Educação Nova, de 1932 (cf. SBPC, 1995), retrata assim o passado imperial e o republicano até então no trecho citado na abertura deste texto.

$\mathrm{O}$ trecho do Manifesto, citado no início, retoma uma passagem de livro de Anísio Teixeira, cujo título bem poderia ser a Escola capitalista no Brasil. Esse trecho denuncia a escola até então existente caracterizada por conter em si dois sistemas ou duas redes opostas. Assumindo a crítica a essa dualidade, o Manifesto opõe a educação a ser (re)construída àquela existente e diz dessa tensão entre o passado/presente e o futuro: 
(...) desprendendo-se dos interesses de classes, a que ela tem servido, deixa de constituir um privilégio determinado pela condição econômica e social do indivíduo, para assumir um "caráter biológico", com que ela se organiza para a coletividade em geral, reconhecendo a todo o indivíduo o direito a ser educado até onde o permitam as suas aptidóes naturais, independente de razões de ordem econômica e social. (1932, p. 33)

O Manifesto buscou combater essa dualidade de redes por meio de uma estrutura educacional sob a égide da escola pública. Com currículos e normas comuns, tendo o Estado como articulador e legislador, o sistema só se diversificaria após uma escolaridade fundamental comum e para todos. E essa diversificação deveria permitir a todos os seus concluintes o prosseguimento de estudos, mormente no ensino superior.

Essa dialética, expressão do conflito social privilégio (das elites) $x$ direito (aberto a todos e a cada um), fará comparecer na Constituição de 1934 a educação como direito, a obrigação dos poderes públicos em prestá-la gratuita no ensino primário e obrigatoriamente nas escolas oficiais, a vinculação de porcentuais dos impostos federativos para a educação escolar, a concessão do Estado para a abertura de escolas sob o regime privado e o estabelecimento de um plano nacional de educação (Rocha, 2001).

Contudo, ainda no jogo privilégio versus direito, no ensino ulterior ao primário, ainda que tendencialmente gratuito, a Constituição de 1934 diz que haverá "limitação da matrícula à capacidade didática do estabelecimento e seleção...”, conforme o artigo 150, letra e. Ou seja, para os que obtivessem seu certificado de conclusão do primário e quisessem prosseguir seus estudos, eles deveriam prestar os conhecidos exames de admissão. E as vagas, além de dependerem dessa seleção, teriam de levar em conta a capacidade didática do estabelecimento. A gratuidade posterior ao primário dependeria de legislação estadual. ${ }^{4}$

O retorno ao privilégio, ao elitismo na destinação social para o secundário/superior, ficaria meridianamente claro com o fim do frágil regime democrático de 1934. Trata-se da ditadura do Estado Novo em 1937 (Horta, 1994). A Constituição outorgada desse regime de facto expressa nos seus artigos 125, 127 e 129, respectivamente, uma explícita visão organicista, hierárquica e elitista da educação e da sociedade: "A educação integral da prole é o primeiro dever e o direito natural 
dos pais. O Estado não será estranho a esse dever, colaborando, de maneira principal ou subsidiária, para facilitar sua execução ou suprir as deficiências e lacunas da educação particular”.

Essa formulação, procedente do jusnaturalismo pré-moderno, assume a família, na educação, como detentora do conjunto da socialização do indivíduo. Ela é uma clara ordenação baseada em um modelo organicista. ${ }^{5}$

A infância e a juventude devem ser objeto de cuidados e garantias especiais por parte do Estado, que tomará todas as medidas destinadas a assegurar-lhes condiçōes físicas e morais de vida sã e de harmonioso desenvolvimento das suas faculdades.

À infância e à juventude a que faltarem os recursos necessários à educação em instituições particulares, é dever da Nação, dos estados e dos municípios assegurar, pela fundação de instituiçōos públicas de ensino em todos os seus graus, a possibilidade de receber uma educação adequada às suas faculdades, aptidões e tendências vocacionais.

Do ponto de vista dessa formulação, a escola privada, extensão da própria família, é a principal rede constitutiva do sistema de ensino. Neste sentido, a constituição de um sistema de educação inverteria a relação público/privado. A rede pública ganharia sua constituição no e a partir do sistema privado.

O ensino pré-vocacional e profissional destinado às classes menos favorecidas é em matéria de educação o primeiro dever do Estado. Cumpre-lhe dar execução a esse dever, fundando institutos de ensino profissional e subsidiando os de iniciativa dos estados, dos municípios e dos indivíduos ou associações particulares e profissionais.

Aqui fica evidenciada a teoria dos dois sistemas paralelos, segundo o trecho do texto de Anísio Teixeira posto no Manifesto, ou como prefere a sociologia educacional francesa: a teoria das duas $\operatorname{redes}^{6}$ não poderia ser mais clara.

E tal teoria teve um novo reforço legal ao mostrar o outro lado da moeda. Trata-se do Decreto n. 4.244/42, em seu artigo 22, relativo aos "herdeiros" da Reforma do Ensino Secundário, afirmando: “(...) é finalidade da educação secundária formar as individualidades condutoras pelo que força é desenvolver nos alunos a capacidade de iniciativa e de decisão e todos os atributos fortes da vontade". 
Por oposição, os destinatários do ensino profissional são os que a Constituição de 1937 denominava, no artigo 129, de classes menos favorecidas.

Há aqui um duplo dualismo: a escola pública é voltada para os que não conseguem entrar em escola particular, a qual, por sua vez extensão da família -, deve ser subsidiada pelo Estado, formando as elites condutoras (cf. Cunha, 2000 e 1981). E a escola pública, voltada para as classes menos favorecidas, tem na educação primário-profissional o seu lugar natural de receber uma educação adequada às suas faculdades, aptidões e tendências vocacionais, segundo o teor do mesmo artigo 129 da Constituição de então.

A Consolidação das Leis do Trabalho (CLT), Decreto-Lei n. 5.452/ 43, em seu artigo 399, prevê o diploma de benemerência às empresas que mantiverem creches e instituições de proteção aos menores em idade pré-escolar... Quase na mesma orientação, o artigo 427 previa aos menores empregados a concessão obrigatória do tempo que fosse necessário para a freqüência às aulas. Já o $\$$ único desse artigo dispunha:

Os estabelecimentos situados em lugar onde a escola estiver a maior distância que dois quilômetros, e que ocuparem, permanentemente, mais de trinta menores analfabetos, de 14 a 18 anos, serão obrigados a manter local apropriado em que lhes seja ministrada a instrução primária.

A empresa com tais características e que não cumprisse esse dispositivo incorria em penalidades expressas em multas.

A superação desse duplo dualismo franco, explícito e seletivo seria objeto de passos lentos, doloridos, em vista da equiparação do ensino profissional com o ensino secundário e a possibilidade de prosseguimento em estudos superiores (Buffa, 1979; Saviani, 1973).

Sob a Constituição de 1946, vários princípios e diretrizes postos na de 1934 retornam ao texto constitucional, inclusive aquele da competência da União em estabelecer as diretrizes e bases da educação. Após debates intensos, profundos e até mesmo apaixonados, entre os segmentos publicistas e os defensores do ensino privado, vem à tona a Lei de Diretrizes e Bases da Educação Nacional, prevista, sob a Lei n. 4.024/ 61 (cf. Machado, 1989a).

Essa lei deixou em aberto brechas para que o ensino primário obrigatório não fosse integralmente cumprido. Seu artigo 30, ao explicitar as isenções da obrigatoriedade, deixa claro quem "não precisa" ser 
Sistema Nacional de Educação: desafio para uma educação igualitária e federativa

destinatário da educação escolar: os que comprovarem estado de pobreza, os que não puderem ir à escola por haver insuficiência de escolas ou por estas já terem suas matrículas encerradas. Além desses casos, incluem-se os indivíduos que estejam com alguma doença ou anomalia grave.

Raramente a face da desigualdade social foi tão clara: o indivíduo em estado de pobreza está privado das virtudes de um direito proclamado como essencial para a vida social. Mas certamente não está excluído de continuar sendo mantido clientelisticamente nos espaços de um trabalho rural. Também o cidadão cujo município ou região do estado careça de recursos para abertura de escolas ou de vagas para todos também pode ser desobrigado da freqüência à escola. Seus cidadãos, contudo, não estão proibidos de serem sujeitos a um trabalho precário.

A frágil Constituição de 1967 subtrai da educação a vinculação, no momento em que essa mesma lei, no seu artigo $168, \$ 3^{\circ}$, inciso II, ampliava o ensino primário para 8 anos e o tornava obrigatório apenas para a faixa etária de 7 a 14 anos. ${ }^{7} \mathrm{E}$ esse é o momento em que a migração rural para os centros urbanos começava a exigir expansão da rede física e uma formação docente que considerasse o novo perfil de aluno entrante nos sistemas públicos, perfil advindo de vários segmentos das classes populares. Com mais crianças nas escolas e menos recursos, a consequiência seria inevitável: a precarização do trabalho docente e das condições de trabalho conduziria a itinerários com evasão e repetência e a um desempenho sofrível.

Dessa época, ainda, tem-se a maior facilidade, sob precários regimes contratuais, de entrada de docentes, nos sistemas de ensino em geral, de formados em instituições destituídas da integração ensino/ pesquisa e de qualidade limitada.

A busca pela redemocratização do país, à vista da brutal desigualdade na redistribuição da renda, à vista de um desenho pouco animador do pacto federativo, conduziu a uma impressionante mobilização popular. Renascem os sonhos, crescem as expectativas, desenha-se a vontade de uma realidade mais promissora, mais democrática e mais justa.

A Constituição de 1988 exibe, na proclamação de direitos da cidadania, na assinalação de novas obrigações do Estado, a vontade de 
fazer, no país, no presente, um acerto de contas com a modernidade, expurgando do passado um enorme passivo com a justiça e com a democracia.

Aí a educação se torna o primeiro dos direitos sociais (art. $6^{\circ}$.), o ensino fundamental, gratuito e obrigatório, ganha a condição de direito público subjetivo para todos, os sistemas de ensino passam a coexistir em regime de colaboração recíproca, a gestão democrática tornase princípio dos sistemas públicos de ensino e a gratuidade, em nível nacional e para todos os níveis e etapas da escolarização pública, tornase princípio de toda a educação nacional (art. 205-214). O texto constitucional reconhece o direito à diferença de etnia, de idade, de sexo e situações peculiares de deficiência, sem abrir mão do princípio da igualdade (Cury, 2005).

O contraste entre a real situação do país, herança secular, e a necessidade de eliminar várias dessas marcas anacrônicas em face da modernidade, das injustiças existentes em face dos direitos sociais proclamados e do autoritarismo em face d democracia ganha relevo e apoio no texto constitucional. Prova disso é o artigo $3^{\circ}$ da Constituição, que põe como objetivos fundamentais do Estado Democrático de Direito a busca por uma sociedade livre, justa e solidária, a redução das desigualdades sociais, das disparidades regionais e das discriminações que ofendem a dignidade da pessoa humana.

Em que pesem os avanços conquistados na educação escolar, desde então, como a proximidade de uma universalização do ensino fundamental, o disciplinamento do financiamento vinculado, a ampliação do ensino médio e a discreta abertura na educação infantil, há muito o que fazer. ${ }^{8}$

Esse processo de produção da desigualdade, de cujo peso a realidade atual ainda é detentora, vai nos mostrando a face dos sujeitos da privação: as classes populares traduzidas nos diversos retratos de trabalhadores manuais, migrantes do campo e de regiōes mais pobres do país, negros, pardos, povos indígenas, moradores de bairros periféricos e pessoas fora da faixa etária legal.

Dessa realidade contrastante emanam as várias posições doutrinárias em busca de uma que faça jus a um conceito de sistema. Um deles, então, é a busca por um sistema que passa a ser adjetivado de sistema único, do qual decorreria a escola unica ou escola unitária (Machado, 1989b). 
É evidente que o desafio de um sistema único de educação se radica no próprio desafio de uma superação da desigualdade. Mas esse desafio não impede a consecução de valores, princípios e normas comuns, além de normas específicas, afirmados no ordenamento jurídico atual. ${ }^{9}$

Hoje, dessa dinâmica da busca por uma escola única, restaram algumas conseqüências importantes: o Estado detentor do monopólio da validade dos certificados e diplomas, detentor exclusivo da autorização de funcionamento de instituiçôes e estabelecimentos escolares, titular das diretrizes e bases da educação nacional e a emersão do conceito de educação básica (Cury, 2008). É por conta desse estatuto que o sistema de educação é público e nele se inclui a rede privada.

Um segundo desafio procede de outra realidade que, por sua vez, por contingências históricas, trará outras barreiras para a constituição de um sistema nacional de educação.

O Brasil, desde a proclamação da República, é uma República Federativa e, como tal, isso supõe um pacto federativo no qual coexistam a união federativa e a pluralidade de entes federados.

Trata-se de um regime em que os poderes de governo são repartidos entre instâncias governamentais por meio de campos de poder e de competências legalmente definidas. A repartição de competências e de pólos múltiplos de poder sempre foi um assunto básico para a elucidação da(s) forma(s) federativa(s) de Estado. Daí as discussōes em torno das variantes da forma federativa e a temática da descentralização.

Ora, no caso da relação educação escolar, Estado(s) e (des)centralização, é preciso retroagir ao Império. Com efeito, nossa primeira lei geral de educação escolar, de 1827, foi a única que atribuiu competência plena aos poderes centrais na educação. Mas a jurisdiçãao sobre a instrução primária, ao regulamentar o artigo da Constituição relativo à gratuidade dessa instrução, trará uma limitação de ordem demográfica e espacial. Seu artigo $1^{\circ}$ diz, ipsis litteris: "Em todas as cidades, vilas e lugares mais populosos, haverão [sic] as escolas de primeiras letras que forem necessárias".

Tal limitação diz respeito ao interior do país, do isolamento da população residente em vastos latifúndios monoculturais, na pecuária e mesmo em regiôes de mineração. Dela se pode extrair uma conseqüência subjacente do tipo: que necessidade há em fornecer educação para essa população? A que ela vai servir? Não será ela inútil para 
tais populações? Neste sentido, a instrução destinar-se-ia, junto com as barreiras sociais assinaladas, aos moradores de espaços urbanos mais populosos.

Contudo, em 1834, o Brasil Imperial conhecerá uma mudança altamente significativa. O Ato Adicional (Lei n. 16, de 12/8/1834), a rigor uma emenda constitucional, passa a dispor certa autonomia para as Províncias, dotando-as de Assembléias Legislativas Provinciais, estabelecendo uma divisão de recursos fiscais, adotando Câmaras dos Distritos e eliminando a figura dos Conselhos Gerais Provinciais.

Conforme o $\$ 2^{\circ}$ do artigo 10 desse ato, houve a adoção de uma descentralização do ensino primário ao atribuir às Províncias competência legislativa sobre a instrução pública e estabelecimentos próprios a promovêla... Já o ensino superior continuava competência dos poderes gerais.

Iniciava-se, em um país imperial e centralizado, uma descentralização educacional e, com ele, uma duplicidade de sistemas de ensino sem a constituição de um sistema nacional. De um lado, os poderes gerais (Corte), com impostos mais elevados, jurisdicionaria o ensino superior, apanágio das elites, e, de outro lado, a instrução primária ficaria a cargo das Províncias, titulares de impostos de menor valor. ${ }^{10}$ Data dessa época o já conhecido "empurra-empurra" quanto a uma clareza maior das competências e do financiamento. Ao comentar esse ato, Sucupira (2001, p. 61-62) assim se pronuncia:

O princípio de descentralização educacional consagrado pelo Ato Adicional não foi aceito pacificamente sem críticas. Juristas, políticos e educadores questionaram a exclusão do poder central do campo da instrução primária e secundária. $\mathrm{O}$ ponto nodal da questão estava em saber se a competência conferida às assembléias provinciais, em matéria de educação, era privativa. Ao que parece, o entendimento dos parlamentares, nos anos imediatos que se seguiram à promulgação do Ato, é que se tratava de uma competência concorrente.

Em 1888, a escravatura foi oficialmente abolida e, a seguir, instaura-se, em 1889, a República Federativa, representativa e presidencialista, com a Constituição de 1891 (Cury, 2001). Silenciando-se sobre a gratuidade em âmbito nacional, ficará a cargo dos estados a possibilidade de se afirmar nas respectivas constituiçôes tanto a gratuidade como, eventualmente, sua associação com a obrigatoriedade. 
A República, passando de um regime centralizado para um descentralizado, adotará um modelo federativo no qual a dualidade União/ estados tem o poder central (União) com poderes limitados e os estados com poderes ampliados. Tornados membros federativos, poderiam exercer sua autonomia ainda que dentro de uma sempre assinalada assimetria de condiçôes econômicas, militares e políticas entre elas.

Foram em vão as várias tentativas legais e pressões sociais, no período da Velha República, pela afirmação nacional e constitucional da gratuidade e de uma maior presença da União no ensino obrigatório, exceto em tentativas de convênio com os estados, pouco sucedidas, no apoio financeiro ao pagamento de salário dos professores atuantes em regiôes rurais. Outra exceção dá-se quando o governo federal nacionaliza e financia as escolas primárias e normais estabelecidas em núcleos de população imigrada no sul do país. ${ }^{11}$

Uma tomada de posição sui generis, dentro da Velha República, ocorrerá com a Reforma Rivadávia Corrêa, em 1911, pela qual há uma verdadeira desoficialização da educação, de tal modo que a abertura de escolas passou a se fazer de modo extremamente flexível. O surto de escolas elétricas foi de tal monta que a Reforma Maximiliano retomou o papel do Estado em matéria de oficialização.

Nem mesmo a Revisão Constitucional de 1925/26, em cujo processo havia emenda no sentido de se estabelecer a gratuidade e a obrigatoriedade do ensino primário público em todos os sistemas de ensino, logrou êxito (Cury, 2003).

A Constituição de 1934, garantida a autonomia dos estados e o sistema federativo, impóe para todos os estados e municípios a instrução primária gratuita e obrigatória no ensino oficial, a vinculação de impostos para o financiamento, assumindo a educação como direito.

A Constituição de 1946 retorna aos princípios maiores do federalismo e aos fundamentos da Constituição de $1934 .^{12}$

O golpe militar de 1964, ao lado de uma maior precariedade no regime federativo, trará novos impactos na educação escolar inclusive com a desvinculação dos impostos para a educação. ${ }^{13}$

Essas realidades se apóiam em um federalismo educacional, trazido pela Lei n. 4.024/61, especificamente entre os artigos 11 e 22, no qual as diretrizes e bases da educação nacional são da alçada da 
União, bem como a rede de ensino superior federal e o ensino superior da rede privada. Os estados poderiam, sob condiçóes, investir concorrentemente com a União no ensino superior. Assim, competia aos estados e aos municípios a efetivação do direito à educação no âmbito do então ensino primário e ensino médio (que hoje são etapas do que a Lei n. 9.394/96 chama de educação básica).

Ora, essa tradição de mais de 164 anos foi criando e sedimentando uma cultura relativa à autonomia dos entes federados, sobretudo dos estados, no âmbito da educação escolar. Tal tradição se apóia não só na maior proximidade entre as fases de vida próprias da educação básica e os gestores das administraçōes estaduais e municipais, mas também nas relações de poder que os vastos sistemas de ensino propiciam em face dos cargos e das funções de confiança, entre os quais o da direção dos estabelecimentos.

Nesse sentido, temos uma organização da educação nacional de acordo com o Título IV da atual LDB e não um sistema nacional. ${ }^{14} \mathrm{Na-}$ cional é a educação, na forma federativa em que comparecem competências privativas, concorrentes e comuns dos entes federativos. ${ }^{15}$

A atual Constituição deu continuidade à tradição advinda do Ato Adicional de 1834 e dispôs pela pluralização dos sistemas, inclusive pela incorporação dos sistemas de ensino municipais (art. 211).

Esses sistemas, coexistentes ao reconhecimento de estados, municípios, Distrito Federal e União como entes federativos, teriam uma articulação mútua organizada por meio de uma engenharia consociativa articulada por um regime de colaboração entre todos eles. Tal engenharia serviria como modo de se evitar a dispersão de esforços e como meio de se efetivar um regime federativo e cooperativo na educação escolar. ${ }^{16}$

Um sistema nacional de educação teria de alavancar o papel da Uniāo com uma maior presença no âmbito da educação básica e no âmbito das redes privadas dos sistemas de ensino. Já em 1988, assinalava Barreto (p. 20):

Cabe à União enfeixar em um todo orgânico o sistema nacional de educação, constituído pelo conjunto de seus sistemas de ensino com vistas a assegurar a continuidade e articulação horizontal e vertical entre os diferentes cursos e níveis, desde a pré-escola até a universidade. Cabe a ela também formular a política nacional de educação, expressa através de 
Planos Nacionais de Educação que incorporem as contribuições dos estados e municípios, dos profissionais da área e dos segmentos majoritários da população organizados. É ainda atribuição da União o estabelecimento de um núcleo comum de conhecimentos que devem constituir a formação escolar nacional básica a que todo cidadão tem de ter acesso, bem como o suprimento das deficiências do ensino, quando estas ocorrem em larga escala. Assim sendo, o governo federal deve contribuir para sanar as extremas diferenças encontradas nos índices de escolarização das distintas regiōes do país, que vêm se mantendo inalteradas por décadas, reforma após reforma educativa.

Nascem daí as dificuldades para a implantação de um "sistema nacional de educação”. Afinal, a organização de um sistema educacional é tanto a busca por organização pedagógica quanto uma via de jogo de poder. Por isso, cada vez que esse assunto foi pautado em constituintes, leis de diretrizes e bases, planos nacionais de educação e fundos de financiamento, ele foi motivo de intensos debates e polêmicas, sobretudo quando o adjetivo nacional entrou em pauta. Seu não-acolhimento se deveu a várias justificativas. ${ }^{17}$

Há um temor de invasão indébita na autonomia dos entes federativos e, com isso, a eventual perda de autonomia destes. Após 164 anos de descentralização, há o medo de uma centralização por parte do Estado federal na qualidade de Estado nacional. Há o receio, por parte do segmento privado na educação escolar, de se ferir a liberdade de ensino e não falta quem assinale o perigo do monopólio estatal. E há também precaução da parte da própria União quanto a uma presença mais efetiva na educação básica, sobretudo no que se refere ao financiamento desta.

Deve-se afirmar que mudanças neste sentido implicam alterações legais para cuja aprovação se deve considerar a tradicional recusa a essa expressão. Se tais reflexóes são pertinentes a um sistema nacional de educação, a provocativa problemática de um sistema único de educação traz à tona o desafio extra-escolar de um país desigual, com um fosso cada vez maior entre ricos e pobres na divisão de renda e no acesso a bens sociais. ${ }^{18}$

Isso posto, há de se levantar um terceiro desafio.

A Constituição de 1988, recusando tanto um federalismo centrífugo como centrípeto, optou por um federalismo cooperativo sob a 
denominação de regime de colaboração recíproca, descentralizado, com funçôes compartilhadas entre os entes federativos de acordo com os artigos $1^{\circ}, 18,23,29,30$ e 211.

Os sistemas de ensino desde logo passaram a usufruir existência legal, ficando a organização e o seu modo de funcionamento sob a esfera da autonomia dos entes federativos, obedecendo ao princípio da colaboração recíproca. ${ }^{19}$

$\mathrm{O}$ artigo $211, \$ 1^{\circ}$, esclarece o regime de colaboração, no que toca à União, por meio de um papel redistributivo, supletivo e equalizador com assistência técnica e financeira aos estados, ao Distrito Federal e aos municípios. $\mathrm{O} \$ 2^{\circ}$ volta-se para os municípios que atuarão prioritariamente no Ensino Fundamental e na Educação Infantil. $\mathrm{O}$ $\$ 3^{\circ}$ esclarece que os estados e o Distrito Federal devem atuar prioritariamente no ensino fundamental e no ensino médio. Isso mostra que o ensino fundamental é uma competência compartilhada, reforçada pelo artigo 10, II, da LDB, que diz ser incumbência dos estados "definir, com os municípios, formas de colaboração na oferta do Ensino Fundamental, as quais devem assegurar a distribuição proporcional das responsabilidades (...)".

Também o mesmo artigo 10, III, estimula a integração das ações relativas a diretrizes e planos de educação estaduais com as iniciativas dos municípios.

A LDB, por sua vez, nos artigos 11 e 18, em consonância com o artigo 211 da Constituição Federal, reconhece, explicitamente, os sistemas municipais de ensino e esclarece suas incumbências em matéria de educação escolar. Entre estas está a de autorizar, credenciar e supervisionar os estabelecimentos do seu sistema de ensino. Ora, esse sistema de ensino compreende também, de acordo com o artigo 18, II, as instituiçōes de educação infantil criadas e mantidas pela iniciativa privada.

Disso tudo decorre que a distribuição de competências, em face dos objetivos maiores da educação escolar, deve ser feita, diferencialmente, dentro do âmbito de aplicabilidade de cada ente federativo e, compartilhadamente, por intermédio do regime de colaboração próprio do novo caráter da federação brasileira. Logo, as relaçōes interfederativas não se dão mais por processos hierárquicos e sim por meio do respeito aos campos próprios das competências assinaladas mediadas e articuladas pelo princípio da colaboração recíproca e dialogal. 
Assim, o pacto federativo dispõe, na educação escolar, a coexistência coordenada e descentralizada de sistemas de ensino sob regime de colaboração recíproca:

- com unidade: artigo $6^{\circ}$ e artigo 205 da $\mathrm{CF} / 88$;

- com princípios comuns: artigo 206 da CF/88;

- com divisão de competências e responsabilidades;

- com diversidade de campos administrativos;

- com diversidade de níveis de educação escolar;

- com assinalação de recursos vinculados;

- com diretrizes e bases da educação nacional: artigo 22, XXIV, da $\mathrm{CF} / 88$;

- com plano nacional de educação: artigo 214 da CF/88.

Decorre daí um caráter de administração complexa em razão do número de espaços e poderes implicados em um regime federativo, do conjunto bastante intrincado da legislação e dos temores supramencionados.

Surgem, então, indicadores que apontam para um sistema nacional, no interior do desenho constitucional formal, ao postular um regime de colaboração recíproca.

Aqui se pode perguntar: se o $\$$ único do artigo 11 da LDB possibilita a integração dos sistemas estaduais e municipais de ensino sob a forma de sistema único de educação básica, por que tal não seria porta aberta para um sistema nacional da educação básica sob as diretrizes e bases da educação nacional? Ademais, não seria lícito inferir que, além da LDB, o Plano Nacional de Educação, o sistema nacional de avaliação, o Conselho Nacional de Educação e o FUNDEB (precedido pelo FUNDEF) não apontam para a necessidade de um sistema nacionalmente articulado?

Em contrapartida, surgem, também, limites e dificuldades para a formalização de um sistema nacional de educação. $\mathrm{O}$ primeiro deles advém da omissão de nossos parlamentares em não terem ainda elaborado a lei complementar, exigida pela Constituição em seu $\$$ único do artigo 23 . 
O segundo limite insere-se dentro dessa omissão. Como estamos com 20 anos de distância da proclamação da Constituição e como em política o vácuo não existe, essa lacuna em efetivar o $\$$ único do artigo 23 vem sendo ocupada por uma guerra fiscal entre os estados, pelas contínuas intromissōes em torno dos recursos financeiros dos entes federativos (como é o caso da Desvinculação dos Recursos da União - DRU) e pelo artifício da imposição disfarçada de impostos denominados de contribuiçôes e que, por isso, não entram nos porcentuais vinculados.

Tudo isso acaba gerando, na prática, não um federalismo cooperativo e mais um federalismo competitivo, que póe em risco o pacto federativo sob a figura da colaboração recíproca e seus potenciais avanços.

Não seria desproposital chamar à cena, nesse momento, a Emenda Constitucional n. 19/98, que prevê uma nova redação para o artigo 241 nos seguintes termos: "A União, os estados, o Distrito Federal e os municípios disciplinarão por meio de lei os consórcios públicos e os convênios, bem como a transferência total ou parcial de encargos, serviços, pessoal e bens essenciais à continuidade dos serviços transferidos".

Esse artigo foi regulamentado pela Lei n. 11.107 de 2005, que estabelece normas gerais de contratação de consórcios públicos. ${ }^{20}$

Além de questionamentos ao teor constitucional dessa lei, tudo indica que ela ampliou o espectro da administração indireta de serviços públicos ao criar a figura do consórcio público seja como pessoa jurídica de direito público (associação pública) ou como pessoa jurídica de direito privado (associação civil).

Essa lei pode configurar-se como algo de superposto ao já previsto regime de colaboração recíproca e constituir-se como um elemento híbrido em campo próprio da administração direta e do dever do Estado, como é o caso da educação escolar.

A rigor, um aperfeiçoamento do FUNDEB, com mais recursos e controle social destes, carrega consigo a possibilidade de uma gestão democrática e compartilhada da educação escolar no sistema público de ensino. Neste sentido, essa lei consorcial não se aplica ao campo da educação escolar, que já conta com um regime legal próprio e potencialmente solidário no âmbito da administração direta. 
Essa complexidade político-jurídico-administrativa coexiste com uma realidade socioeducacional muito desigual e da qual decorrem incertezas sobre a escassez de recursos.

Um sistema de educação supõe, como definição, uma rede de órgãos, instituiçôes escolares e estabelecimentos - fato; um ordenamento jurídico com leis de educação - norma; uma finalidade comum valor; uma base comum - direito.

Esses quatro elementos devem coexistir como conjunto, como conjunto organizado, como conjunto organizado sob um ordenamento, como conjunto organizado sob um ordenamento com finalidade comum (valor), como conjunto organizado sob um ordenamento com finalidade comum (valor) sob a figura de um direito.

Essa coexistência, pois, supõe unidade e diversidade, essa coexistência supõe unidade e diversidade sem antinomias (ausência de incompatibilidades normativas). Ou, nos termos de Ferraz (1984, p. 9-10):

Ao conjunto assim organizado dá-se o nome de sistema de ensino. Se desmembrarmos o conceito identificando-lhe e agrupando-lhe os elementos ou componentes essenciais, aí vamos encontrar as quatro causas tratadas na filosofia aristotélico-tomista: a) a causa material, a matéria de que é feito o sistema (pessoas, coisas recursos); b) a causa formal, as normas (leis, decretos-leis, decretos e outros atos da autoridade competente) que dão forma orgânica a tal matéria; c) o órgão do Poder Público ao qual incumba atuar como causa eficiente, dando organização ao sistema; d) a causa final, os fins ou valores (éticos, políticos, religiosos, econômicos, pedagógicos, etc.) em vista dos quais o sistema se organiza.

Então, a proposta de um sistema nacional de educação, explicitamente formulado, gera várias perguntas:

1. Pode haver uma coordenação mais clara e mais direta pela União de modo que se exerçam as funções equalizadora e redistributiva?

2. Como aprimorar as competências dos sistemas de modo que se propicie um exercício harmônico do regime de colaboração sob a coordenação mais incisiva da União?

3. O sistema nacional propiciaria a melhoria dos resultados em relação à aprendizagem e à socialização de valores? 
O Plano Nacional de Educação, Lei n. 10.172/01, no capítulo sobre financiamento - um dos pilares de um sistema nacional -, diz claramente em suas Diretrizes a propósito dessa matéria:

Para que a gestão seja eficiente há de se promover o autêntico federalismo em matéria educacional, a partir da divisão de responsabilidades previstas na Carta Magna. A educação é um todo integrado, de sorte que o que ocorre num determinado nível repercute nos demais, tanto no que se refere aos aspectos quantitativos como qualitativos (...). Portanto, uma diretriz importante é o aperfeiçoamento contínuo do regime de colaboração.

A dimensão de direito da cidadania ao direito à educação, seja por um sistema nacional, seja por um sistema de fato atualmente praticado, não poderá fugir da resposta ao que o PNE chama de "autêntico federalismo". Semelhante ao princípio da igualdade - horizonte maior da cidadania - posto na Constituição para contrastar com o fato intolerável da desigualdade existente, o princípio de um federalismo "autêntico" se contrasta com o "inautêntico" colhido na realidade dos fatos.

Então, o que é um federalismo autêntico? Qual o caminho entre o horizonte da autenticidade e o real inautêntico para que aquele supere este?

A sociedade brasileira, pela mediação do Estado, espera dos educadores em geral, dos estudiosos do assunto e dos próprios legisladores uma resposta a esta pergunta que não quer calar, ou seja, por que não afirmar um sistema nacional de educação para o acontecer de uma educação com qualidade?

Recebido em maio de 2008 e aprovado em agosto de 2008.

\section{Notas}

1. De acordo com Martins (1997, p. 30-31), “(...) tivemos duas escravidóes: a indígena e a negra, cada uma regulada por um estatuto jurídico diferente. (...) É no século dezoito, porém, que se dá uma cessação mais ou menos eficaz da escravidão indígena. O Diretório dos Índios do Maranhão e do Grão-Pará liberta os índios administrados, nome que tinha a sua escravidão. Eles passam, então, à condição de teoricamente livres e, na prática, mais ou menos servos dependentes do grande proprietário. Milhōes de indígenas foram vítimas de extenso genocídio". 
2. A Corte, no ano de 1849 , era habitada por 78.855 escravos e 10.732 libertos, representando $43 \%$ da população total, segundo Karasch (1979).

3. Vê-se que o artigo $3^{\circ}$ é antinômico à Constituição Imperial, que tinha os libertos como cidadãos. Contudo, ele expressa uma suspeição preconceituosa quanto aos libertos, decorrerte de sua origem, e desconfiança com relação aos seus comportamentos.

4. A gratuidade no ensino primário, presente na Constituição Imperial, não consta da primeira Constituição Republicana, de 1891. Tal possibilidade seria da jurisdição das constituições estaduais.

5. Para uma visão do modelo organicista, cf. Bobbio e Bovero (1986).

6. Referência ao livro de Baudelot e Stablet (1977).

7. A Lei n. 5.692/71 nomeia o ensino primário de 8 anos como ensino de $1^{\circ}$ grau e mantém a faixa etária de 7 a 14 anos.

8. Considere-se, por exemplo, os vetos à ampliação do financiamento público para a educação escolar impostos ao Plano Nacional de Educação pelo Poder Executivo, em 2001, ou, então, os vetos para que a Educação de Jovens e Adultos se beneficiasse do esquema do FUNDEF.

9. No âmbito do direito à saúde, o artigo 198 da Constituição confirma um sistema único das açōes e serviços públicos da saúde.

10. Em 1840, a Lei n. 105, de 12 de maio de 1840, interpreta, de modo conservador e centralizador, o Ato Adicional de 1834. Em 1841, com a Lei n. 234, de 23 de novembro, há o retorno do Conselho de Estado com conselheiros vitalícios, nomeados pelo imperador.

11. Esta é a primeira intervenção direta e financiada da União no ensino primário, por meio do Ministério da Justiça, nos estados do Paraná, do Rio Grande do Sul e de Santa Catarina, respectivamente, mediante os decretos: n. 13.175, de 6/9/1918, n. 13.390, de 8/1/1919, e n. 13.460 , de 5/2/1919.

12. Sobre federalismo e educação, cf. Cury (2006). Sobre essa Constituição, cf. Oliveira (2001).

13. O retorno da vinculação dá-se, primeiro, na emenda da Junta Militar de 1969, exclusivamente para os municípios, e, depois, com a emenda Calmon (EC n. 24/83), seguida da Lei n. 7.348/85.

14. Não faltam nem argumentos procedentes para a defesa desse ponto de vista, nem propostas neste sentido (cf. Saviani, 1999).

15. A Constituição de 1988 adota a expressão sistema nacional para o emprego no artigo 22, IX, e fala no sistema financeiro nacional no Título VII, capítulo IV. Pode-se dizer que boa parte do artigo 21 e do artigo 22, salvo casos de autorização, permissão e concessão, possui uma dimensão nacional.

16. Cf., a esse respeito, o Parecer CNE/CEB n. 30/00.

17. Mesmo com a indicação de uma lei complementar que traduza o regime de cooperação recíproca, posta no $₫$ único do artigo 23 da Constituição de 1988, até hoje essa lei não foi efetivada.

18. A Constituição de 1988, no Título VIII, capítulo II, seção II, artigo 198, versando sobre a saúde, diz que "as ações e serviços públicos de saúde integram uma rede regionalizada e hierarquizada e constituem um sistema único (...)”. 
19. Cf., sobre o assunto sistemas de ensino e sistemas municipais, o Parecer CNE/CEB n. 30/00.

20. Essa lei tem sido articulada, até o presente, com as diretrizes nacionais de saneamento básico, conforme a Lei n. 11.445/07, e com o programa de cooperação federativa para a constituição da força nacional de segurança pública, conforme o Decreto n. 5.289/04.

\section{Referências}

ANDRADE, C.D. Política literária. In: Andrade, C.D. Alguma poesia: poesia e prosa. Rio de Janeiro: Nova Aguilar, 1979. p. 80.

BARRETO, E.S.S. O ensino fundamental na política nacional de educação: alguns aportes. Em Aberto, Brasília, DF, v. 7, n. 38, p. 12-21, abr./jun. 1988 .

BAUDELOT, C.; STABLET, R. La escuela capitalista. México, DF: Siglo Veintiuno, 1977.

BOBBIO, N.; BOVERO, M. Sociedade e Estado na filosofia política moderna. São Paulo: Brasiliense, 1986.

BUFFA, E. Ideologias em conflito: escola pública e escola privada. São Paulo: Cortez \& Moraes, 1979

CUNHA, C. Educação e autoritarismo no Estado Novo. São Paulo: Cortez, 1981.

CUNHA, L.A. O ensino profissional na irradiação do industrialismo. São Paulo: UNESP; Brasília, DF: FLACSO, 2000.

CURY, C.R.J. Cidadania republicana e educação: governo provisório do mal; Deodoro e Congresso Constituinte de 1890-1891. Rio de Janeiro: DP\&A, 2001.

CURY, C.R.J. A educação na Revisão Constitucional de 1925-1926. Bragança Paulista: EDUSF, 2003.

CURY, C.R.J. Os fora-de-série na escola. Campinas: Autores Associados, 2005.

CURY, C.R.J. Federalismo político e educacional. In: Ferreira, N.S.C.; Schlesener, A. (Org.). Políticas públicas e gestão da educação: polêmicas, fundamentos e análises. Brasília, DF: Líber Livro, 2006. 
CURY, C.R.J. A educação básica como direito. 2008 (no prelo).

FÁVERO, O. (Org.). A educação nas constituintes brasileiras. 2. ed. Campinas: Autores Associados, 2001.

FERRAZ, E.F. Conceituação de sistema de ensino. In: SouZA, P.N.P.; SILVA, E.B. (Org.). Educação: escola - trabalho. São Paulo: Pioneira, 1984.

HORTA, J.S.B. O hino, o sermão e a ordem do dia: regime autoritário e educação no Brasil. Rio de Janeiro: UFRJ, 1994.

INSTITUTO BRASILEIRO DE GEOGRAFIA E ESTATISTICA (IBGE). A estatística e a organização nacional. Revista Brasileira de Estatística, Rio de Janeiro, v. 2, v. 1, jan./mar. 1941.

KARASCH, M.C. A vida dos escravos no Rio de Janeiro, 1808-1850. São Paulo: Cia das Letras, 1979.

MACHADO, L.R.S. Educação e divisão do trabalho. São Paulo: Cortez, 1989a.

MACHADO, L.R.S. Politecnia, escola unitária e trabalho. São Paulo: Cortez, 1989b.

O MANIFESTO dos pioneiros da educação nova, de 1932. In: SBPC Documenta, n. 3. A (re)construção da educação no Brasil. São Paulo: SBPC, 1995. p. 27-50.

MARSHALL, T.H. Cidadania, classe social e status. Rio de Janeiro: Zahar, 1967.

MARTINS, J.S. Exclusão social e a nova desigualdade. São Paulo: Paulus, 1997.

OLIVEIRA, R.P. A educação na Constituinte de 1946. In: FÁvero, $\mathrm{O}$. (Org.). A educação nas constituintes brasileiras. 2. ed. Campinas: Autores Associados, 2001.

PRZEWORSKI, A. Capitalismo e social-democracia. São Paulo: Cia das Letras, 1989.

ROCHA, M.B.M. Tradição e modernidade na educação: o processo constituinte de 1933-34. In: FÁvero, O. (Org.). A educação nas constituintes brasileiras. 2. ed. Campinas: Autores Associados, 2001. 
SAVIANI, D. Educação brasileira: estrutura e sistema. São Paulo: Saraiva, 1973.

SAVIANI, D. Sistemas de ensino e planos de educação: o âmbito dos municípios. Educação \& Sociedade, Campinas, v. 20, n. 69, p. 119136, dez. 1999.

SUCUPIRA, N. O Ato Adicional e a descentralização da educação. In: FÁvero, O. (Org.). A educação nas constituintes brasileiras. 2. ed. Campinas: Autores Associados, 2001. 